УДК $2.23 / 28+395+397+398$

DOI: $10.17223 / 19988613 / 50 / 20$

\title{
В.А. Бурнаков
}

\section{ТРАДИЦИОННОЕ МИРОВОЗЗРЕНИЕ ХАКАСОВ В ИССЛЕДОВАНИИ СВЯЩЕННИКА М. АЛЕКСАНДРОВА}

\begin{abstract}
Впервые рассматривается малоизвестная этнографическая работа православного священника М. Александрова «О религиозном миросозерцании Минусинских инородцев», которая была издана в 1888 г. в журнале «Енисейские епархиальные ведомости». Стремясь улучшить прозелитическую деятельность среди хакасов, этот исследователь-миссионер сделал попытку глубже изучить их традиционное мировоззрение и обрядность. В результате ему удалось воссоздать наиболее полную картину архаичных религиозно-мифологических представлений хакасов, бытовавшую в последнем десятилетии ХІХ в.

Ключевые слова: хакасы; христианизация; миссионеры; прозелитизм; традиционное мировоззрение; обрядность; фольклор.
\end{abstract}

Как известно, на культуру хакасов немалое влияние оказало христианство (православие). Более того, к концу XIX в. они все официально считались православными. В связи с этим в церковных и административных документах они зачастую обозначались как «крещенные инородцы / татары».

Вопросы, связанные с христианизацией хакасов, привлекали внимание многих исследователей. В работах ученых обозначенная научная проблема рассматривалась преимущественно в рамках истории обращения в православие коренного населения Хакасии. Исследовались объективные обстоятельства этого процесса, а также стратегии, формы, методы и этапы. Большое внимание при этом уделялось анализу вопросов формирования структуры церковной организации в указанном регионе. Помимо того, была затронута и тема влияния православия на духовную жизнь хакасов, в том числе на их мировоззрение и обрядность [1-7].

Вместе с тем приходится констатировать и то, что, несмотря на достаточную изученность многих граней указанной проблематики, вопросы, связанные с анализом непосредственно этнографических изысканий православных миссионеров, следует признать практически неосвещенными. Характеризуя их труды, отметим определенную тенденциозность в их восприятии и интерпретации культуры хакасов (как и других сибирских народов). Особенно это касается такого ее проявления, как традиционное мировоззрение и ритуальная сфера, которые воспринимались ими заведомо как «поганое язычество», «языческая фантазия», «народные суеверия и предрассудки», «вековое мракобесие», идолопоклонство, поклонение дьяволу, сатанизм и пр. Подобный предвзятый подход неминуемо приводил к абсолютному упрощению и значительному искажению в восприятии и понимании этого сложного и глубинного явления. Между тем необходимо признать, что, несмотря на всю субъективность оценок, они, тем не менее, внесли заметный вклад в освещение обозначенной темы. Ценность собранных ими данных прежде всего определяется их фактологией. В наши дни получить подобные сведения ввиду утраты многих черт тради- ционной культуры, а в отдельных случаях и даже памяти о них, к сожалению, уже не представляется возможным. Однако они по-прежнему сохраняют свою актуальность и в наши дни. На это указывает их востребованность многими современными исследователями из смежных областей гуманитарных знаний - историками, этнографами, религиоведами, культурологами, психологами и др.

Представленная статья посвящена рассмотрению вклада в этнографию, в частности в изучение традиционного мировоззрения и обрядности хакасов, православного священника М. Александрова.

Миссионерство, как известно, было ключевым направлением служебных обязанностей православного духовенства. Многолетний опыт прозелитической деятельности выявил следующий факт. Эффективность и глубина внедрения православия в иноэтническую среду, главным образом в сознание людей, прежде всего определялись полнотой знаний об их психологии, образе мышления и ценностях. В соответствующее информационное поле непременно должны были входить данные о жизненных реалиях и интересах обращаемого в православие народа и, безусловно, его мировоззренческие основания. Более того, необходимо было еще и практически применить эти знания в духовной практике. Именно эта мысль стала одной из ключевых на епископском соборе, состоявшемся в 1885 г. в г. Казани. Она была выражена следующим образом: «Как можно научить и просветить людей, о которых мы не знаем, что и как они думают, каких укоренившихся суеверий, предрассудков, унаследованных исстари держаться? Священник должен иметь представление о мыслях инородца как об обыденных предметах, так и о предметах, стоящих выше обыденной жизни, о духовном; иначе он будет бороться с чем-то неизвестным, а неизвестную опасность преодолеть нельзя» [8. 1888. № 6. С. 81].

Сформулированный и озвученный на соборе новый подход в концепции миссионерства был призван способствовать выработке особых тактических приемов в прозелитизме. В ее основе лежала нацеленность на выработку и применение наиболее эффективных методов 
и форм взаимодействий с автохтонным населением, стремление глубже изучить и проанализировать их жизнь во всем ее многообразии. Как показала практика, наиболее успешными миссионерами становились те священнослужители, которые искренне и глубоко интересовались жизнью и потребностями сибирских народов, принимали самое активное участие в их судьбе и помогали в разрешении насущных жизненных проблем. Немаловажным в этом деле было и знание языка своей иноэтничной паствы. Определенные надежды распространялись и на внедрение практики христианской проповеди на их родном языке.

Большие ожидания в миссионерском деле возлагались также и на способы передачи непосредственно самого вероучения. Их важнейшими характеристиками непременно должны были быть простота и доступность в изложении его основных догматов, при этом не искажающем глубинной сути православного вероучения. Безусловно, все это требовало соответствующих обширных знаний и компетентной адаптации основополагающих религиозных идей к ментальному уровню христианизируемых обществ и, главным образом, к их базовым жизненным ценностям. Решение поставленных задач представлялось невозможным без необходимых лингвистических и этнографических познаний. Обозначенное требование уже априори вынуждало отдельных представителей духовенства обращаться к изучению культурных особенностей коренных сибиряков, акцентировать внимание на специфике их психологии, мышления и языка. Подобная установка стала мотивирующей для М. Александрова при написании указанной работы. Он отмечал, что «с вопросов о просвещении язычников (очень немногих) и язычествующих христиан - минусинских инородцев, кроме изучения и применения к делу языка местных инородцев, тесно связан еще вопрос об изучении местным духовенством и будущими пастырями в инородческих приходах - религиозного миросозерцания и быта минусинских татар» [8. 1888. № 6. С. 80].

Следует признать, что в действительности лиц, в полной мере соответствовавших обозначенным критериям, было крайне мало, а тех, кто бы еще и владел «инородческим наречием», хотя бы на элементарном бытовом уровне вообще, - единицы. Между тем отдельные миссионеры, имея многолетний опыт прозелитической деятельности среди сибирских народов, знали предмет своего исследования не только в теории, но и на практике. В результате наиболее энергичным и целеустремленным из них в ходе проповеднической деятельности удалось собрать оригинальные и весьма ценные этнографические материалы. Из числа наиболее известных исследователей-священнослужителей, которые в рамках своей духовной деятельности еще и изучали культуру хакасов, следует выделить: Н. Путилова $[9,10]$, Н.А. Орфеева [11. 1885. № 23, 24], М. Александрова [8. 1888. № 6, 8-9, 12-18], Н. Катанова [12], В. Суховского [13], П. Тыжнова [14] и пр.
Среди историко-этнографических работ названных представителей духовенства, пожалуй, одной из наиболее примечательных является труд М. Александрова «О религиозном миросозерцании Минусинских инородцев» ${ }^{1}$. Необходимо заметить, что названный автор один из немногих православных священников, который, несмотря на свой духовный сан и обусловленные этим твердые и ясные религиозные убеждения, в процессе работы над темой все же стремился следовать принципам научной объективности. В отличие от других миссионеров, он акцентировал основное внимание не на собственной субъективной оценке традиционных верований и обрядности хакасов и соответственно их разгромной критике, а непосредственно на фактологической стороне этого явления культуры.

Несомненно, следует признать и то, что в исследовании М. Александрова отсутствуют собственные полевые материалы. В результате в процессе работы над проблемой он вынужденно обращался к полевым этнографическим материалам, собранным другими исследователями, в том числе и миссионерами, например к работам Н. Орфеева, В. Вербицкого и пр. В отличие от многих своих коллег - православных священнослужителей - при подготовке публикации он постарался скрупулезно проработать всю доступную для него литературу по интересующему вопросу, сделал попытку систематизации собранных материалов.

Так, обосновывая актуальность своего труда, М. Александров писал: «Ввиду важности вопроса об изучении верований и быта инородцев, мы попытались собрать в одно - все, что известно в печати о религиозном миросозерцании минусинских инородцев. Пусть люди, близко стоящие к инородцам, проверят и дополнят полученные нами из скудной литературы о минусинских татарах данные. Главными источниками для определения религиозного миросозерцания минусинских татар нам служили - памятники народной литературы - поэмы и сказки» [8. 1888. № 6. С. 81].

К сказанным словам добавим то, что в своей работе он опирался не только на опубликованные материалы по устному народному творчеству хакасов, но также использовал историко-этнографические труды и лингвистические исследования таких известных ученых, как: И.Г. Гмелин, Э. Реклю, М.А. Кастрен, А.А. Шифнер, И.Н. Березин, Н.А. Костров, В.И. Вербицкий, Л.С. Чудновский, В.В. Радлов, Г.Н. Потанин, Н.М. Ядринцев, Н.Ф. Катанов и др. Безусловно, названными именами в действительности же не ограничивается круг исследователей XVIII-XIX вв., в той или иной мере изучавших историю и культуру хакасов. Заметим, что среди неупомянутых ученых остались, например, Д.Г. Мессершмидт, И.Г. Георги, Г.Ф. Миллер, П.С. Паллас, Г. Спасский, А.П. Степанов, Н.С. Щукин и др. Тем не менее для священнослужителя, по своей сути не являвшегося профессиональным исследователем-историком, опубликовать подобную статью, очевидно, уже само по себе было большим достижением. И, несо- 
мненно, данный факт для своего времени выступал показателем его высокого уровня образованности, помимо того, демонстрировал достаточную глубину подхода в изучении проблемы.

Невольно обращает на себя внимание и одновременно приятно удивляет то, что в процессе написания текста своей объемной статьи он добросовестно придерживался этики научного цитирования. Все ссылки на труды исследователей и фольклорные материалы им были строго соблюдены и выверены. Заметим, что подобного этического принципа даже не всегда придерживались и придерживаются многие светские авторы в прошлом, да и в современности. Данное обстоятельство убедительно позиционирует его как серьезного и глубокого исследователя. Безусловно, все это ярко выделяет его среди остальных православных священников, в той или иной мере занимавшихся изучением традиционного быта и верований хакасов в XIX в.

Труд М. Александрова «О религиозном миросозерцании Минусинских инородцев» был опубликован в известном в Сибири церковном периодическом издании - «Енисейские епархиальные ведомости». Необходимо пояснить, что данный журнал являлся ежемесячным официальным изданием Енисейской духовной консистории, который начал издаваться с 1884 г. [5. С. 20]. По своему внутреннему содержанию он состоял из двух отделов - официального и неофициального. В первом отделе размещались документы, имеющие общецерковное значение, а также распоряжения епархиального начальства. Регулярно печатались извлечения из отчетов о состоянии епархии и различные темы, связанные с церковнослужителями и духовным образованием. Во втором отделе печатались проповеди, поучения и речи, а также статьи, посвященные истории епархии, ее храмам, святыням, местным святым, отчеты и личные наблюдения миссионеров и др. [16]. Заметим и то, что именно в неофициальной части издания в разные годы были опубликованы материалы и остальных вышеназванных священнослужителей.

Этнографическое сочинение М. Александрова представляет собой объемную статью (свыше 1,5 п.л.), изданную в 1888 г. отдельными частями на протяжении девяти номеров. Сама авторская постановка темы и заявленная цель исследования направлена на рассмотрение традиционного мировидения / мировоззрения хакасов. В качестве основного источника, как уже было отмечено, выступают фольклорные тексты богатырские сказания (aльımmыz нылмахтар) и сказки (нымахтар), собранные и опубликованные Н.Ф. Катановым, В.И. Вербицким, Г.Н. Потаниным. Рассматриваемый труд, исходя из структуры и логики изложения, может быть условно дифференцирован на четыре смысловые части.

В первой главе представлены самые общие сведения о хакасах, в том числе об их языковой принадлежности и традиционных верованиях. Не будучи профессиональным исследователем-тюркологом, М. Алексан- дров всецело опирается на полевые исследования и выводы таких известных этнографов и лингвистов, как М.А. Кастрен и В.В. Радлов. Он констатировал тот факт, что местное население в обозначенное время состояло из четырех основных групп: качинцев, сагайцев, койбалов и кызыльцев. Вслед за В.В. Радловым идентифицирует их в качестве «абаканских татар», к которым причисляет и кызыльцев, но с оговоркой на то, что они все же локализованы не в Минусинском, а в Ачинском округе. Характеризуя рассматриваемую этнокультурную общность в рамках концепции упомянутого ученого, Александров отмечает ее сложный внутри этнический состав: «Абаканские татары произошли, вообще говоря, “из самой пестрой смеси племен, но долговременное житье бок о бок, друг с другом и одинаковость образа жизни сплотило их в одно общее целое"» [8. 1888. № 6. С. 2].

Затрагивая языковой вопрос, автор сообщил о том, что в настоящий момент все представленные группы говорят на тюркском языке, в связи с чем в качестве одного из вариантов их идентификации привел такой, как «минусинские тюрки» [Там же].

Вызывает интерес то обстоятельство, что М. Александров в своей работе использовал сравнительноисторический метод исследования. В качестве сравнительно-сопоставительного материала он привлек этнографические и лингвистические сведения о соседнем и родственном хакасам народе - алтайцах (алтайских тюрках). Поясняя данный исследовательский подход, он сообщал: «Ввиду сходства языка и верований минусинских татар с языком и верованиями алтайских инородцев, мы сочли нужным, где нужно, отметить это сходство. Алтайские инородцы лучше изучены, чем минусинские. Непонятные и отрывочные сведения о миросозерцании минусинских инородцев - лучше объяснять более ясными сведениями об алтайских инородцах» [Там же. С. 81].

Рассматривая вопросы, обусловленные языковыми особенностями этих народов, он обратился к трудам своего коллеги - известного лингвиста и этнографа миссионера В.И. Вербицкого, который классифицировал язык «минусинских татар» как принадлежащий к «отрасли аладагского наречия», «распространенного в Кузнецком округе», т.е. родственный и в целом понятный северным алтайцам, шорцам и телеутам. Исходя из обозначенной реалии, на страницах журнала «Енисейские епархиальные ведомости» М. Александров активно призывал священнослужителей Минусинского и Ачинского округов к широкому применению этнолингвистических наработок алтайского миссионера для популяризации христианства и более эффективной проповеднической деятельности среди коренных жителей: «Это знать весьма важно нашим миссионерам и священникам инородческих приходов Минусинского округа, потому что, по заявлению Вербицкого, алтайскими миссионерами язык алтайцев изучен достаточно; они составили грамматику этого языка и сравнитель- 
ный подробный словарь всех наречий и подречий алтайских и аладагских. Желающие могут воспользоваться трудами алтайской миссии для целей более успешного просвещения наших минусинских инородцев» [8. 1888. № 6. С. 80]. Заметим, что в то время для миссионеров незнание языка местных жителей выступила острой, а в отдельных случаях и непреодолимой проблемой ввиду того, что в подавляющем своем большинстве хакасы, особенно проживавшие в отдаленных поселениях - аал'ах, абсолютно не владели русским языком.

М. Александров, следуя выводам, сформулированным в результате проведенных полевых исследований П.С. Палласа и В.В. Радлова, констатирует факт того, что основная масса хакасов лишь формально считаются крещенными. В действительности же они все еще оставались убежденными приверженцами и практиками своих традиционных верований и обрядности. Изучая и постепенно углубляясь в данную тему, он вынужден констатировать следующую реалию. Несмотря на наличие отдельных работ, вопросы, связанные с традиционной культурой и бытом хакасов, на тот период все еще остаются слабо изученными [Там же. С. 81].

Следуя поставленной цели - воссоздать перед читателями более полную картину архаичных религиозномифологических представлений этого народа и соответственно по возможности заполнить недостающие лакуны, как уже было сказано, он активно привлекал алтайские этнографические материалы. Отметим, что на тот момент они были гораздо шире представлены в исторической и публицистической литературе. Обосновывая применяемый им метод сравнительноисторической реконструкции, М. Александров, прежде всего, исходил из исторической общности указанных народов, что находило свое отражение в чрезвычайной близости и сходстве их культур, образа жизни, языка и миропонимания. Он давал следующую краткую характеристику их мировоззренческим системам: «Хотя сведения относительно религиозных верований и суеверий инородцев Минусинского округа не полны и отрывочны; однако, сопоставляя их с наиболее тщательно исследованным религиозным миросозерцанием алтайских инородцев, во многих отношениях сходных с инородцами минусинских степей, мы можем предположить, что верования минусинских татар - пантеизм и политеизм: у них есть обоготворенная природа, бестелесные духи и богигерои» [Там же. № 8-9. С. 94].

Далее, анализируя систему мировоззрения хакасов, автор не без оснований выявляет в нем наличие дуалистических представлений. Светлое начало представлено в лице $X y \partial a$ 'я - доброго божества, обитающего на небе. А темное - Эрлик-ханом (Айна хан) - злое божество, локализованное в подземном мире. Представленные сведения совершенно точно соответствуют концепции традиционного мировидения хакасов, согласно которой весь земной мир, а значит, и сам человек на протяжении всей своей жизни находится под постоян- ным воздействием этих двух противоположных сил. При этом в религиозно-мифологическом сознании народа дихотомия добра и зла все же не имеет полной абсолютизации. Верующие в равной мере вынуждены были взаимодействовать с двумя началами. Особое положение в этой мировоззренческой системе отводится духам-хозяевам природных объектов, в частности духам гор - maz ээзі. Общей и чрезвычайно лаконичной характеристикой религиозно-мифологической картины мира хакасов завершается первая часть его работы [8. 1888. № 8-9. С. 94-95].

Вторая часть статьи М. Александрова посвящена де-

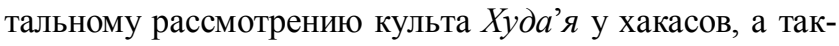
же представлениям о небожителях. Автор, используя результаты лингвистических исследований Н.Ф. Катанова, сообщил об древнеиранских корнях этого термина, обозначающего понятие «Бог». При этом он обратил внимание на то, что в культуре хакасского народа представленная дефиниция имеет своеобразное понимание [Там же. С. 95-97]. В своей глубинной сути она разительно отличается от идеи Бога, представленной в русском православном мировосприятии. Так, в традиционном сознании хакасов под словом Худай было принято понимать, во-первых, персонифицированную высшую светлую силу, нередко именуемую также «Улуг Худай» - 'Великий / Старший Бог (Всевышний)' или «Ax Xyдай» - 'Белый / Светоносный Бог'. Отметим

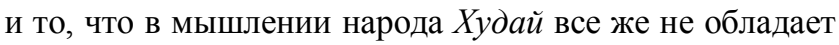
природой Абсолюта. Его сакральные возможности весьма ограничены. Для разрешения определенных жизненно важных задач он обращается к посторонней помощи, чаще к услугам избранных людей (в фольклоре это земные богатыри - aльл' 'bl). Во-вторых, лексему

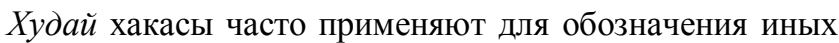
небесных божеств, стоящих рангом гораздо ниже Улуг Худа'я. Причем обозначенный термин неразрывно употребляется с такими числительными, как: семь - 'читі' (Читі Худай) и девять - 'товысс' (Товыс Худай). Худа'u, таким образом, представляют собой своеобразную иерархию высших небесных сил. М. Александровым было подмечено и то, что синонимом к слову «Худай» нередко выступает «Чайаан» - 'Творец', которое обычно выступает в качестве эпитета. Данная реалия, безусловно, нашла отражение в языковой картине мира хакасов, например «Чайаан Худай» - 'Бог-творец, создатель', «Ӧоркі Чайаан» - 'Всевышний', «Чогархы турван Товыс Чайаан» - 'Живущие на небе девять богов-творцов' [17. С. 925], «Чир Чайаан»- 'Творец земли’, «Читі Чайаан» - ‘Семь творцов’ и др. Этот термин одинаково часто используется как в обыденной речи, так и в произведениях устного народного творчества.

В русле интерпретации рассматриваемых религиозно-мифологических персонажей, предложенной Г.Н. Потаниным, М. Александров был склонен видеть в них олицетворение отдельных небесных светил, в частности «Созвездие Большой Медведицы». Помимо того, он отметил еще и сакрализацию солнца и луны, 
которые осмыслялись хакасами как персонифицированные божества. В их отношении была сформирована специальная обрядность [8. 1888. № 8-9. С. 95-96; № 12. С. 155].

Исследователь совершенно верно подметил такую особенность традиционных представлений хакасов о сверхъестественных существах, как их антропоморфизация: «Место жительства и образ жизни добрых богов в сказках минусинских татар представляется слишком человекообразно» [Там же. С. 97]. Действительно, в

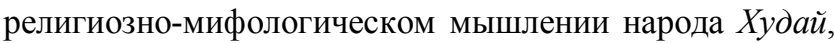
как и другие представители Верхнего - небесного мира, наделяются антропоморфными чертами. Причем не только их внешний облик, но и вся их система жизнедеятельности является своеобразной калькой человеческого бытия. Более того, подобное суждение переносится на все сферы мироздания. В дальнейшем эту особенность мировосприятия подтвердили и сибирские этнографы, сообщавшие о том, что «в мифологии тюрков Южной Сибири оба мира, «небесный» и «подземный», - копии с одной матрицы - «среднего мира». В них реальный мир дважды повторяет себя, в первом случае абсолютизируя положительное, а во втором отрицательное начала, уравновешивающие друг друга в общей картине мира» [18. С. 16].

В третьей части своей работы М. Александров достаточно подробно останавливается на воззрениях хакасов о Среднем - земном мире [8. 1888. № 13. С. 179183; № 14. С. 198-201]. Сравнивая их представления с алтайскими, он приходит к выводу об их чрезвычайной схожести, относительно чего сообщает, что «природа обоготворяется минусинскими татарами, как и алтайцами. По верованиям тех и других, у каждой долины, горы, реки есть свой дух - эзе» [Там же. № 13. С. 179]. Отметим полное соответствие этих утверждений традиционным взглядам народа, согласно которым Средний мир населяют земные люди и духи (ээзі): хозяева гор - тав ээлері, воды - сув ээлері, огня - оттың ээзі / om ине и пр. По верованиям хакасов, они, находясь в непосредственной близости от людей, оказывают на них наибольшее влияние. Причем характер их воздействия положительный или отрицательный, во многом определяется самим человеком, главным образом его мыслительной, речевой и поведенческой активностью. Заметим, что к подобной же мысли, на примере духа-хозяина гор / тайги, пришел и представленный автор, писавший, что «горные духи скорее добрые существа, чем злые. Злыми они разве являются по отношению к людям неблагодарным или к тем, которые во время охоты ходят шумно по лесу, тем тревожат горного духа и показывать, значит, к нему непочтенье» [Там же. С. 180].

Исследователь обратил особое внимание и на развитый культ гор у хакасов: «Почему-то горные духи некоторыми инородцами чествуются, как покровители рода» [Там же]. Данная мысль совершенно точно подтверждается этнографическими реалиями. Согласно хакасским поверьям, горные духи воспринимались в качестве мифических предков и покровителей родов, в связи с чем каждый сӧӧк (род) в летнее время у своей родовой святыни с разной периодичностью совершал обряд жертвоприношения родовому духу-хозяину горы - maz maйblz. Причем ритуал отправлял исключительно лишь шаман.

Не прошли мимо исследовательского взора М. Александрова и такие составляющие религиозномифологической системы хакасов, как почитание тӧс'ов - семейно-родовых и иных духов, изображаемых в виде идолов [8. 1888. № 14. С. 198]. Сверхъестественные существа и олицетворяющие их фетиши сибирских народов обычно воспринимались русскими в качестве языческих идолов «нечистой силы» и обычно обозначались словом «шайтаны». Töc'bl размещались как внутри жилища, так и за его пределами [19].

Помимо того, автором были отмечены и тотемистические представления хакасов: «У минусинских инородцев находят следы почитания животных и растений. Объяснением некоторых случаев такого рода чествования могут служить предания относительно происхождения некоторых инородческих родов и колен от животных, птиц или даже деревьев» [8. 1888. № 14. С. 198-200]. В свете изучения сакральных объектов земного пространства был рассмотрен и культ почитания каменных изваяний. Автор, ссылаясь на материалы Д.А. Клеменца, пишет, что «современными минусинскими татарами оказывается религиозное почитание вообще каменным бабам» [Там же. С. 201]. Большое внимание им уделено изучению верований и обрядности, связанной с Улуг Хуртуях Тас - 'Великой каменной бабушкой'.

Последняя, четвертая часть посвящена подробному рассмотрению представлений хакасов о Нижнем - подземном мире и его обитателях, а также воззрениям о душе человека. Здесь подтверждается факт того, что рассматриваемое пространство обладает большим сходством со Средним - земным миром. В связи с чем автор констатировал, что «подземное царство имеет свои горы, степи, реки, моря и проч. Значит, в изображении подземного царства инородцы пользуются картинами земного видимого мира» [Там же. № 15. С. 217]. При этом указывается его многослойность. Число подземных ярусов достигает семнадцати [Там же].

Сообщается, что главными персонажами - жителями Нижнего мира - выступают злые духи во главе с Эрлик-ханом и души умерших людей. Между тем М. Александров, используя в своей работе материалы Н. Орфеева, вслед за ним допускает ошибку в интерпретации суждений хакасов об Эрлик-хане, айна, шайтане. Она заключается в том, что обозначенные сверхъявственные существа рассматриваются им в качестве разных и самостоятельных лиц [Там же. № 15, 16, 17, 18]. Так, выражая данную мысль, он пишет: «Подземных духов, как это можно заключить из имеющихся у нас под руками данных, великое множество, из них особенно выделяются, как главные злые духи, айна, 
эрлик-хан и шайтан. Относительно первых двух известно, что они под своим начальством и в своем распоряжении имеют подчиненных второстепенных злых духов. Это же, пожалуй, нужно сказать и относительно шайтана. Кроме данных, заключающихся в самой мифологии минусинских татар, основанием считать айну, эрлик-хана и шайтана главнейшими из злых божеств может служить сравнение религии минусинских татар с религиями других шаманистов» [8. 1888. № 15 . C. 217-218].

На самом же деле, как свидетельствуют данные религиозно-мифологических представлений хакасов, владыкой подземного мира выступает лишь Эрлик хан [20]. Он имеет семь / девять помощников, также именуемых эрликами. В шаманской поэзии его также называли «Адам / Aдазы»» - 'Отец'. Нередко употребляли и такой эпитет, как «Айна хан» - 'Царь злых духов'. Заметим, что непосредственно сам термин айна не был строго привязан к одному религиозномифологическому лицу. Он распространялся на всю категорию зловредных духов независимо от локализации. Слово «шайтан» не имело внутри этнического распространения и в основном использовалось лишь русскими для обозначения разнообразных персонажей хакасского пандемониума [Там же].

М. Александров останавливается и на рассмотрении мифологических сюжетов с такими персонажами Нижнего мира, как: ведьма Xуy Xam, исполинская рыба Кир Пальхх и многоголовое чудовище - Чельбиген. Помимо того, автор касается и вопроса о посмертной судьбе умерших и идеи воздаяния, описывая картину мучения душ людей в аду [8. 1888. № 18. С. 266-271].

Исследователь в своей работе, безусловно, не смог пройти мимо фигуры шамана и его обрядовой деятельности. Была затронута тема шаманской атрибутики, в частности бубна. В результате изучения данного вопроса он пришел к справедливому выводу о том, что в этом культовом предмете в художественной форме получили воплощение представления хакасов о мироздании и его обитателях [Там же. № 14. С. 199].

Священник М. Александров, подытоживая свое повествование, констатирует: «Из собранного в этой статье материала видно, приблизительно, насколько велик сонм богов - высших и низших, населяющих небо, землю и преисподнюю; сколь много разных духов и чудовищ, требующих жертв, умилостивления, задабривания. Злые божества и их служители, чудовища, наводят на инородца суеверный панический страх» [Там же. № 18. С. 270].

Следует отметить, что в конце своей работы он все же не смог полностью отойти от миссионерского подхода при изложении этнографических материалов. Очевидно, что это было и невозможно при их публикации в религиозном издании. Автор-священнослужитель, вопреки стремлению к научности в освещении обозначенной темы, как основной вывод своего труда считает традиционное мировоззрение хакасов язы- ческим суеверием и «болезней души человеческой», для исцеления которой призывает обратиться в православие. Он завершает свой труд в духе пастырского наставления: «История показывает, что суеверный страх к разным злым существам, созданным языческою фантазией, не скоро вытесняется даже христианским мировоззрением. Отсюда видно, какого внимания пастырей заслуживают суеверия инородцев» [8. 1888. № 18. С. 270-271].

Итак, представленный материал позволяет сделать вывод о том, М. Александров на фоне многих представителей местного духовенства отличался высоким уровнем образования и исследовательскими способностями. Обращаясь к изучению традиционного мировоззрения хакасов, он прежде всего ставил главной целью сделать миссионерскую деятельность наиболее результативной. Существенным препятствием в утверждении хакасского населения в православной вере, как показывала действительность, выступало их нежелание отказаться от веры предков, которую те исповедовали на протяжении столетий.

Как известно, чтобы эффективно бороться с какимлибо явлением, надо прежде всего обладать наиболее полными знаниями о нем. Однако реалии на тот момент были таковы, что православное духовенство, да и сама этнографическая наука, обладало лишь отрывочными, весьма скудными и разрозненными сведениями об этом культурном явлении. Автор посредством систематизации фактических сведений разных исследователей по этой проблеме сделал попытку заполнить образовавшуюся лакуну. Для решения поставленной цели довольно успешно был использован метод сравнительно-исторического анализа, привлекая материалы по алтайской этнографии.

Рассматриваемая статья М. Александрова, по сути, явилась одной из первых этнографических работ XIX в., в которой относительно полно была воссоздана картина мира хакасов. На основе обобщения и анализа имеющегося в его распоряжении материала им совершенно справедливо была выделена вертикальная модель мироздания, состоящая из трех основных сфер: Верхней (небесной), Средней (земной) и Нижней (подземной). Он достаточно подробно проанализировал представления об обитателях каждой из этих частей мироздания и ритуальном сопровождении, связанном с ними. Отметим, что подобной схемы анализа традиционного мировоззрения в дальнейшем практически неукоснительно придерживались и последующие исследователи данной темы.

Таким образом, своей работой священник внес значительный вклад не только в миссионерскую деятельность, но и в этнографическое изучение культуры хакасского народа. Несмотря на то что изучение его традиционного мировоззрения им было осуществлено сквозь призму христианского мировидения, в определенной мере эта работа способствовала установлению информационного контакта между коренным и русским православным населением обозначенного региона. 


\title{
ПРИМЕЧАНИЯ
}

\begin{abstract}
${ }^{1}$ В работе А.Н. Гладышевского «К истории христианства в Хакасии» [5. С. 44] сообщается, что авторство данной работы принадлежит священнику В. Суховскому. Однако в действительности статья была опубликована под фамилией М. Александров. Данное противоречие исследователь никак не объяснил и не привел никаких убедительных доводов в доказательство своего утверждения. Отметим и то, что он также допускает ошибку, приписывая статью «Остатки языческой обрядности у кивинских инородцев» В. Суховскому [5. С. 44; 15. С. 296-300]. Хотя на самом деле она была подготовлена другим миссионером - Петром Суховским. Все это дает основания предполагать, что М. Александров это все же не псевдоним Василия Суховского, а совершенно иной автор. К сожалению, более подробных сведений о нем к настоящему времени обнаружить не удалось.
\end{abstract}

\section{ЛИТЕРАТУРА}

1. Потачаков К.М. Культура и быт хакасов в свете исторических связей с русским народом. Абакан, 1958.160 с.

2. Шибаева Ю.Ш. Влияние христианизации на религиозные верования хакасов // Христианство и ламаизм у коренного населения Сибири (вторая половина ХІХ - начало ХХ в.). Л. : Наука, 1979. С. 180-196.

3. Бутанаев В.Я. Традиционная культура и быт хакасов. Абакан, 1996. $221 \mathrm{c.}$

4. Бутанаев В.Я. Бурханизм тюрков Саяно-Алтая. Абакан : Изд-во ХГУ, 2003. 260 с.

5. Гладышевский А.Н. К истории христианства в Хакасии. Абакан : Типогр. ООО «Фирма-Март», 2004. 136 с.

6. Асочакова В.Н. Христианизация хакасов в XVIII веке - 1861 г. (до образования Енисейской епархии). Абакан: Изд-во ХГУ им. Н.Ф. Катанова, 2008. 248 с.

7. Бурнаков В.А. К вопросу о христианизации хакасов в прошлом и настоящем // Проблемы межэтнического взаимодействия в Сибири. Новосибирск : Изд-во ПреПресс-Студио, 2005. Вып. 3. С. 66-74.

8. Александров М. О религиозном миросозерцании Минусинских инородцев // Енисейские епархиальные ведомости. 1888: № 6. С. 78-81; № 89. C. 94-101; № 12. C. 155-157; № 13. C. 178-183; № 14. C. 198-201; № 15. C. 216-218; № 16. C. 230-232; № 17. C. 246-250; № 18. C. 266271.

9. Путилов Н. (Опубликован как П.Ф.Т.) Встреча с шаманом. Нечто о шайтанах // Енисейские епархиальные ведомости. 1884. № 13. С. 176182.

10. Путилов Н. Шаманы в роли врачей // Енисейские епархиальные ведомости. 1885. № 17. С. 310-311.

11. Орфеев Н. Брачные обычаи инородцев Минусинского округа // Енисейские епархиальные ведомости. 1885. № 23. С. $365-369 ;$ № 24.

12. Катанов Н. (священник). Шаманский бубен и его значение // Енисейские епархиальные ведомости. 1889. № 6. С. 112-114.

13. Суховский В. О шаманстве в Минусинском крае. Отдельный оттиск. Казань, 1901. 9 с.

14. Тыжнов П. Призывание духов камами при нагорном жертвоприношении минусинских инородцев. Шаманство камов над больным. Тур или бубен. Арба. Шаманская одежда (конролыг тон). Шапка шамана (чалынмалалых пюрих) // Енисейские епархиальные ведомости. 1902. № $11-12$. С. $338-344$

15. Суховский П. Остатки языческой обрядности у кивинских инородцев // Енисейские епархиальные ведомости. 1884. № 21. С. 296-300.

16. Древо: открытая православная энциклопедия. URL: http://www.drevo-info.ru/articles/19624.html, свободный (дата обращения: 14.09.2016).

17. Хакасско-русский словарь. Новосибирск : Наука, 2006. 1114 с.

18. Традиционное мировоззрение тюрков Южной Сибири. Пространство и время. Новосибирск : Наука, 1988.225 с.

19. Бурнаков В.А. Роль культовых предметов в социокультурной коммуникации хакасов: по данным языка, культуры и психологии (конец XIX - середина ХХ в.) // Гуманитарные науки в Сибири. 2015. Т. 22, № 2. С. 89-94.

20. Бурнаков В.А. Эрлик-хан в традиционном мировоззрении хакасов // Археология, этнография и антропология Евразии. 2011. № 1 (45). C. $107-114$.

Burnakov Venariy A. Institute of Archaeology and Ethnography of the RAS (Novosibirsk, Russia), Novosibirsk State University (Novosibirsk, Russia).E-mail: venariy@ngs.ru

\section{THE TRADITIONAL WORLDVIEW OF THE KHAKAS IN THE STUDY OF THE ORTHODOX PRIEST} M. ALEKSANDROV.

Keywords: Khakas; Christianization; missionaries; proselytizing; traditional outlook; ritual; folklore.

The aim of the article is to study the little-known ethnographic work of the Orthodox priest M. Aleksandrov "On the Religious worldview of the Minusinsk Natives". To achieve this goal, the following tasks were set: identification of motivation and methods of studying the traditional outlook and ritual practice of the Khakass people, analysis of the source base that served to write the indicated work and the characteristics of the main research results. The chronological scope of the study is limited to the second half of the 19th century - the time when the very study of the spiritual culture of this people was done. The work is based on an integrated, systemhistorical approach to the study of the past. The research method based on historical and ethnographic methods - scientific description, concrete historical and relict. In the process of studying this cultural phenomenon, he used and systematized extensive ethnographic materials: historical, ethnographic and folklore (heroic legends - alypty nymkhtar and fairy tales - nymakhtar). To achieve the goal, he was one of the first to use a comparative-historical method of investigation. As a comparative material he attracted ethnographic and linguistic information about the neighboring and related Khakass people - the Altaians (Altai Turks). Because of the analysis, the following conclusions can be drawn: 1) Missionary activity in Khakassia by the end of the 19th century reached its peak, during which almost all the indigenous population converted to Orthodoxy; 2) Along with this, the degree of penetration of this creed into the consciousness of local residents and their spiritual practice can be characterized as superficial. This reality explained mainly by the administrative approach in the process of their Christianization. In turn, this contributed to their indifference to the religion imposed from above. Christianized Khakass, in fact, remained a pagan, adhering to traditional religious and mythological beliefs; 3) The Russian Orthodox Church used a new strategy to improve the efficiency of proselytizing activities among the indigenous people. Clergymen try to study their language and culture more deeply, including, traditional outlook and ritual. The received knowledge called to help in the spiritualeducational activity among the "aliens" and significantly increase its effectiveness; 4) Within the framework of this missionary installation, the priest M. Alexandrov conducted the study of the marked topic; 5) His work "On the religious worldview of the Minusinsk Natives" was one of the first ethnographic studies of the XIX century, in which the picture of the Khakass world was recreated purposefully and relatively full and structural. Author's development of the analysis of the traditional world outlook was later widely used by subsequent researchers of this problem; 6) By his work, this priest made a significant contribution not only to missionary work, but also to ethnographic study of the culture of the Khakass people. Despite the fact that the study of its traditional worldview was carried out 
through the prism of the Christian worldview, to some extent this work contributed to the establishment of information contact between the indigenous and Russian Orthodox population of the designated region.

\section{REFERENCES}

1. Potachakov, K.M. (1958) Kul'tura i byt khakasov, v svete istoricheskikh svyazey s russkim narodom [Culture and life of the Khakass in the light of historical ties with the Russian people]. Abakan: [s.n.].

2. Shibaeva, Yu.Sh. (1979) Vliyanie khristianizatsii na religioznye verovaniya khakasov [The influence of Christianisation on the religious beliefs of the Khakas]. In: Vdovin, I.S. (ed.) Khristianstvo i lamaizm u korennogo naseleniya Sibiri (vtoraya polovina XIX - nachalo XX v.) [Christianity and Lamaism in the indigenous population of Siberia (second half of the 19th - early 20th centuries)]. Leningrad: Nauka. pp. 180-196.

3. Butanaev, V.Ya. (1996) Traditsionnaya kul'tura i byt khakasov [Traditional culture and life of Khakassians]. Abakan: Khakasskoe kn. izd-vo.

4. Butanaev, V.Ya. (2003) Burkhanizm tyurkov Sayano-Altaya [Burhanism of the Turks of Sayano-Altai]. Abakan: Khakass State University.

5. Gladyshevskiy, A.N. (2004) K istorii khristianstva v Khakasii [To the history of Christianity in Khakassia]. Abakan: Firma-Mart.

6. Asochakova, V.N. (2008) Khristianizatsiya khakasov v XVIII veke - 1861 g. (do obrazovaniya Eniseyskoy eparkhii) [Christianization of the Khakas in the 18th century -1861 (before the formation of the Yenisei diocese)]. Abakan: Khakass State University.

7. Burnakov, V.A. (2005) K voprosu o khristianizatsii khakasov v proshlom i nastoyashchem [On the issue of Christianisation of the Khakas in the past and the present]. In: Fursova, E.L. et al. Problemy mezhetnicheskogo vzaimodeystviya v Sibiri [Problems of interethnic interaction in Siberia]. Novosibirsk: PrePress-Studio. pp. 66-74.

8. Aleksandrov, M. (1888) O religioznom mirosozertsanii Minusinskikh inorodtsev [On the religious worldview of the Minusinsk Non-Russians]. Eniseyskie eparkhial'nye vedomosti. 6 . pp. $78-81$.

9. Putilov, N. (1884) Vstrecha s shamanom. Nechto o shaytanakh [Meeting with the shaman. Something about the Shaytans]. Eniseyskie eparkhial'nye vedomosti. 13. pp. 176-182.

10. Putilov, N. (1885) Shamany v roli vrachey [Shamans in the role of doctors]. Eniseyskie eparkhial'nye vedomosti. 17. pp. 310-311.

11. Orfeev, N. (1885) Brachnye obychai inorodtsev Minusinskogo okruga [Marriage customs of Minusins Non-Russians]. Eniseyskie eparkhial'nye vedomosti. 23. pp. 365-369.

12. Katanov, N. (1889) Shamanskiy buben i ego znachenie [Shaman Tambourine and Its Importance]. Eniseyskie eparkhial'nye vedomosti. 6. pp. 112114.

13. Sukhovskiy, V. (1901) O shamanstve v Minusinskom krae [About shamanism in the Minusinsk Territory].Kazan: [s.n.].

14. Tyzhnov, P. (1902) Prizyvanie dukhov kamami pri nagornom zhertvoprinoshenii minusinskikh inorodtsev. Shamanstvo kamov nad bol'nym. Tur ili buben. Arba. Shamanskaya odezhda (konrolyg ton). Shapka shamana (chalynmalalykh pyurikh) [Calling of spirits by kamas at the mountainous sacrifice of the Minasinian non-Russians. Shamanism of kamas over the sick. Tour or tambourine. Arba. Shaman clothing (konrolyg ton). Shaman's cap (chalynmalalyh piurich)]. Eniseyskie eparkhial'nye vedomosti. 11-12. pp. 338-344.

15. Sukhovskiy, P. (1884) Ostatki yazycheskoy obryadnosti u kivinskikh inorodtsev [Remains of pagan rites in the Kivinsky foreigners]. Eniseyskie eparkhial'nye vedomosti. 21. pp. 296-300.

16. Drevo-info.ru (n.d.) Drevo: otkrytaya pravoslavnaya entsiklopediya [Drevo: An Open Orthodox Encyclopedia]. [Online] Available from: http://www.drevo-info.ru/articles/19624.html. (Accessed: 14th September 2016).

17. Subrakova, O.V. (ed.) (2006) Khakassko-russkiy slovar' [Khakass-Russian Dictionary]. Novosibirsk: Nauka.

18. Gemuev, I.N. (ed.) (1988) Traditsionnoe mirovozzrenie tyurkov Yuzhnoy Sibiri. Prostranstvo $i$ vremya [Traditional Worldview of the Turks of Southern Siberia. Space and Time]. Novosibirsk: Nauka.

19. Burnakov, V.A (2015) The role of religious objects in sociocultural communications of Khakassia: evidence from liguistic data, culture and psychology (the late 19th - mid 20th centuries). Gumanitarnye nauki v Sibiri-Humanitarian sciences in Siberia. 22(2). pp. 89-94. (In Russian).

20. Burnakov, V.A. (2011) Erlik-khan v traditsionnom mirovozzrenii khakasov [Erlik Khan in the traditional world view of Khakass]. Arkheologiya, etnografiya i antropologiya Evrazii - Archaeology, Ethnology \& Anthropology of Eurasia. 1(45). pp. 107-114. 